\title{
On the formation of intermetallics in Fe-Al system - An in situ XRD study
}

\author{
Pavel Novák ${ }^{\mathrm{a}, *}$, Alena Michalcováa ${ }^{\mathrm{a}}$, Ivo Marek ${ }^{\mathrm{a}}$, Martina Mudrováb ${ }^{\mathrm{b}}$, Karel Saksl ${ }^{\mathrm{c}}$, Jozef Bednarčík ${ }^{\mathrm{d}}$, \\ Petr Zikmund ${ }^{\mathrm{e}}$, Dalibor Vojtěch ${ }^{\mathrm{a}}$ \\ a Institute of Chemical Technology, Prague, Department of Metals and Corrosion Engineering, Technická 5, 16628 Prague 6, Czech Republic \\ ${ }^{\mathrm{b}}$ Institute of Chemical Technology, Prague, Department of Computing and Control Engineering, Technická 5, 16628 Prague 6, Czech Republic \\ ${ }^{\mathrm{c}}$ Institute of Materials Research, Slovak Academy of Sciences, Watsonova 47, 04353 Košice, Slovakia \\ ${ }^{\mathrm{d}}$ Deutsches Elektronen-Synchrotron (HASYLAB), Hard X-ray Diffraction Scattering, Notkestr. 85, D-22607 Hamburg, Germany

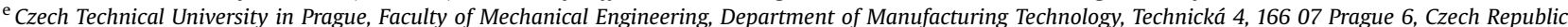

\section{A R T I C L E I N F O}

\section{Article history:}

Received 12 April 2012

Received in revised form 31 July 2012

Accepted 1 August 2012

Available online

\section{Keywords:}

A. Iron aluminides (based on $\mathrm{FeAl}$ )

C. Reaction synthesis

C. Powder metallurgy, including

consolidation

F. Diffraction (electron, neutron and X-ray)

\begin{abstract}
A B S T R A C T
Self-propagating high-temperature synthesis (SHS) was previously proposed as alternative preparation route for $\mathrm{Fe}-\mathrm{Al}$ intermetallics. However, this process was not optimized and the mechanism and kinetics of the phases' formation was not fully clarified up to current days. In this work, in situ high energy X-ray diffraction analysis was carried out during the SHS process and the mechanism of the intermetallic' formation in FeAl25 powder mixture was described during rapid heating and isothermal annealing at $800^{\circ} \mathrm{C}$ as well as during a slower continuous heating to $900^{\circ} \mathrm{C}$. During slower heating, the formation of $\mathrm{Fe}_{2} \mathrm{Al}_{5}$ and $\mathrm{FeAl}_{2}$ intermetallics starts below the melting point of aluminium. When the heating rate is high, intermetallics are created after melting of aluminium. During long-term annealing, all of the phases can be transformed to $\mathrm{FeAl}$ phase when fine powders were applied. Detailed mechanism is proposed in this paper and kinetics of the intermetallics' formation is described.
\end{abstract}

(c) 2012 Elsevier Ltd. All rights reserved.

\section{Introduction}

Materials based on $\mathrm{Fe}-\mathrm{Al}$ system have been known to metallurgists for more than 100 years. In 1890's, the positive effect of aluminium addition on the high-temperature oxidation resistance of iron was discovered [1]. In this time, a continuous development of iron-aluminium alloys began. However, low room-temperature ductility and problematic production of these materials by conventional melting processes limit their applicability up to current days. There were many attempts to overcome the above mentioned limitations [2-5], while one of them is the powder metallurgy using reactive sintering [6,7]. In this process, intermetallics are produced by thermally-activated in situ reactions during sintering of compressed elemental powder mixtures. The big advantage of this technology is the initiation of the reactions leading to the formation of $\mathrm{Fe}-\mathrm{Al}$ intermetallics at significantly lower temperature than the melting temperature of iron and $\mathrm{Fe}-\mathrm{Al}$ phases. In addition to this fact, the $\mathrm{Fe}+\mathrm{Al}$ reactions are strongly exothermal and the evolved heat sustains and propagates further reaction across the compressed powder mixture [8]. Therefore, this

\footnotetext{
* Corresponding author.

E-mail address: panovak@vscht.cz (P. Novák).
}

process is also called Self-sustainable High-temperature Synthesis (SHS) [6]. Due to highly exothermal nature of the processes, this technology is less energy-consuming than common melting metallurgy and conventional powder metallurgy using pre-alloyed powders [8]. In the case of iron-aluminium alloys, extremely high porosity is achieved, especially when pressureless reactive sintering is applied (over $25 \mathrm{vol} . \%$ ) [9]. There are many theories aiming to explain this behaviour, many of them are opposing. These theories find the reason of the unacceptable porosity in the sequence of the formation of intermetallics and ordered solid solutions [6,10-12] or in Kirkendall's effect [13-15].

Fe-Al system (Fig. 1) contains these equilibrium phases [16]: $\mathrm{Fe}-\mathrm{Al}$ melt, solid solution of aluminium in bcc iron, solid solution of iron in fcc aluminium, $\mathrm{Fe}_{3} \mathrm{Al}$ and $\mathrm{FeAl}$ ordered solid solutions and $\mathrm{FeAl}_{2}, \mathrm{Fe}_{2} \mathrm{Al}_{5}$ a $\mathrm{FeAl}_{3}$ intermetallic compounds (Fig. 1). At high temperatures $\left(1002-1232{ }^{\circ} \mathrm{C}\right) \varepsilon-\mathrm{Fe}_{5} \mathrm{Al}_{8}$ phase [17] and solid solution of aluminium in fcc iron are stable. From this list, $\mathrm{Fe}_{3} \mathrm{Al}$ and FeAl ordered phases are of the greatest importance for technical applications.

When $\mathrm{FeAl}$ and $\mathrm{Fe}_{3} \mathrm{Al}$ phases are being produced by powder metallurgy using reactive sintering, it can be expected that interdiffusion of iron and aluminium will occur and ordered phases will be formed after being heated to sufficient temperature. Simultaneously, the densifying of the material by sintering of powder 


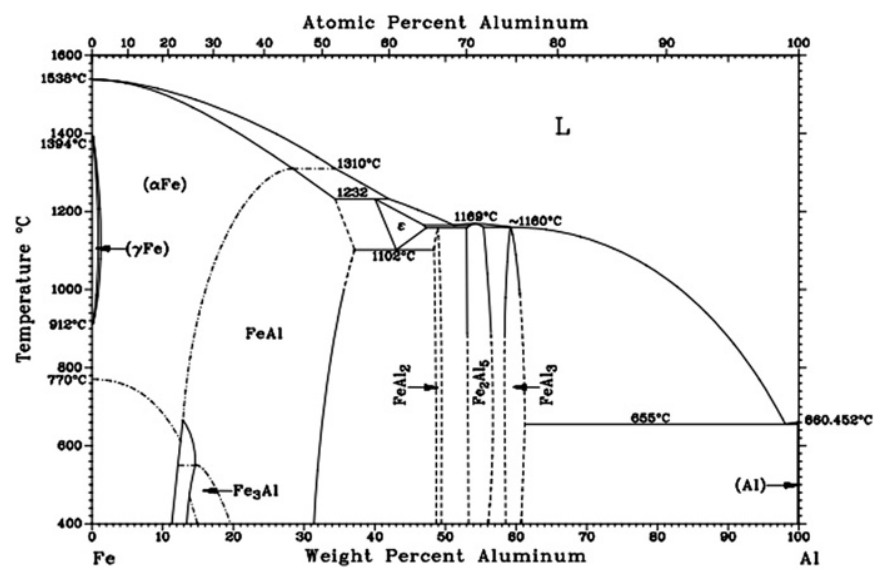

Fig. 1. Fe-Al equilibrium phase diagram [13].

particles would happen as e.g. during the production of steel by powder metallurgy. Real situation is totally different due to a high porosity of the product [6,9]. In addition to this problem, the phase composition of the reactive-sintering produced $\mathrm{Fe}-\mathrm{Al}$ alloys does not correspond to single-phase $\mathrm{FeAl}$ or $\mathrm{Fe}_{3} \mathrm{Al}$ even though the ratio of Fe:Al powders is in accordance with their stoichiometry [6,18].

The literature data about the types of phases present during and after reactive sintering and in their influence on the porosity are very variable. In 1992 it was published [19] that $\mathrm{FeAl}_{3}$ phase is formed by the $\mathrm{Fe}+\mathrm{Al}$ solid state reaction below the melting temperature of aluminium. After that, remaining aluminium particles melt and are enriched by iron. Consequently, other $\mathrm{Fe}-\mathrm{Al}$ phases precipitate from the melt.

A paper from 1995 [20] shows that reactive sintering in air produces a mixture of FeAl ordered phase and aluminium oxide. When the reaction of the powder mixture with identical composition was carried out in vacuum, $\mathrm{FeAl}, \mathrm{Fe}_{3} \mathrm{Al}$ a $\mathrm{FeAl}_{2}$ or a mixture of unreacted iron and $\mathrm{FeAl}_{3}$ phase were determined in dependence on the process conditions [20]. These results are in a strong disagreement with both newer and older papers [10-12,21] presenting the formation of $\mathrm{Fe}_{2} \mathrm{Al}_{5}$ phase. According to ref. [12], $\mathrm{Fe}_{2} \mathrm{Al}_{5}$ phase is formed by a solid state reaction of iron and aluminium at $500{ }^{\circ} \mathrm{C}$. During continuous heating it completely disappears at $850{ }^{\circ} \mathrm{C}$ by a transformation to $\mathrm{Fe}_{3} \mathrm{Al}$ phase. Jozwiak at al. [6] then describe even a $\mathrm{FeAl}_{3} \rightarrow \mathrm{Fe}_{2} \mathrm{Al}_{5} \rightarrow \mathrm{FeAl}_{2} \rightarrow \mathrm{FeAl}$ sequence, beginning at the temperature lower than $600{ }^{\circ} \mathrm{C}$. On the other hand, Hibino at al. [22] stated that aluminium melts before the formation of intermetallics. After that, $\mathrm{Fe}_{2} \mathrm{Al}_{5}, \mathrm{Fe}_{2} \mathrm{Al}_{3}$ and $\mathrm{FeAl}$ phases are gradually formed. Porosity is usually explained by volume changes in the structure resulting from lattice and density differences between the temporary and final phases [12]. The other presented explanation of the enormous porosity is the Kirkendall phenomenon [13-15]. It can be observed when the rates of diffusion of reacting metals ( $\mathrm{Fe}, \mathrm{Al})$ strongly differ [12]. In that case, unidirectional diffusion of one metal is compensated by vacancies diffusion. Coalescence of vacancies produces pores. Detailed explanation of the porosity formation during reactive sintering of $\mathrm{Fe}-\mathrm{Al}$ powder mixture is given in [15]. This study deals with slow heating process aiming to avoid the SHS reaction and to produce porous product.

However, all of the above described results and theories are based on the ex-post study after the reactive sintering only. In some cases, the XRD study of the product was extended by the thermal analysis showing thermal effects of the reactions [6]. There were also several in-situ XRD studies presented in the literature [23-26]. The work of Brajpurya et al. [26] describes the phases' evolution in deposited Fe/Al multi-layers during annealing at $300{ }^{\circ} \mathrm{C}$.
Surprisingly, only FeAl phase was observed in this system. No other transient phases were detected. The in-situ XRD studies of mechanically activated pressure-assisted SHS process also provided very variable results. In ref. [24,25], the direct formation of FeAl phase is stated. On the other hand, the formation of $\mathrm{Fe}_{2} \mathrm{Al}_{5}$ was observed in ref. [27] being continuously transformed to FeAl phase. During the process, $\gamma$-Fe was also detected. Authors concluded that $\mathrm{Fe}_{2} \mathrm{Al}_{5}$ phase is formed before melting of aluminium. This conclusion, being probably influenced by other published papers, is not fully supported by the XRD results showing disappearing of $\mathrm{Al}$ diffraction lines followed by the formation of $\mathrm{Fe}_{2} \mathrm{Al}_{5}$ phase. Almost in all papers, fine powders of both iron and aluminium or coarser iron and finer aluminium powders were applied. In our previous works dealing with $\mathrm{Fe}-\mathrm{Al}, \mathrm{Fe}-\mathrm{Al}-\mathrm{Si}$ and $\mathrm{Ti}-\mathrm{Al}-\mathrm{Si}$ systems it was found that the use of coarser aluminium particles can significantly influence the SHS process [28-30]. Therefore this study is focused on the in-situ study of the pressureless reactive sintering of compressed mixture of fine iron $(<10 \mu \mathrm{m})$ and coarse aluminium powder $(200-600 \mu \mathrm{m})$.

\section{Experimental}

Our first approach to the description of the reaction mechanism in $\mathrm{Fe}-\mathrm{Al}$ system consisted in the thermal analysis of FeAl25 (in wt.\%) compressed powder mixture. Analyses were performed in two modes - slow continuous heating from the room temperature to $900{ }^{\circ} \mathrm{C}$ and isothermal tests at $800^{\circ} \mathrm{C}$. In the first mode, differential thermal analysis (DTA) was used to reveal the thermal effects accompanying the phases' formation during heating of the compressed powder mixture. In these experiments, fine iron powder (particle size $<10 \mu \mathrm{m}$, purity $99.7 \mathrm{wt} . \%$ ) and coarse irregular particles of aluminium (particle size 200-600 $\mu \mathrm{m}$, purity 99.95 wt.\%) prepared by mechanical machining were applied. Powders were blended, compressed with the pressure of $260 \mathrm{MPa}$. Cylindrical samples of $12 \mathrm{~mm}$ in diameter and approx. $6 \mathrm{~mm}$ in height were prepared. DTA was carried out in the argon atmosphere with the rate of $10 \mathrm{~K} \mathrm{~min}^{-1}$ by using Setaram Setsys Evolution - 1750. For this analysis, $75 \mathrm{mg}$ of compressed sample was separated and used.

In the isothermal mode, the above described cylindrical compressed powder mixtures were heated to $800{ }^{\circ} \mathrm{C}$ with the rate over $400 \mathrm{~K} \mathrm{~min}^{-1}$ and isothermally annealed at this temperature. Such a high heating rate was obtained by placing the sample to the preheated furnace. Due to the limitations of the DTA, thermal camera FLIR T640 was applied to monitor the temperature changes during the reactions. In this mode, two powder sizes of iron ( $<10 \mu \mathrm{m}$ and $<250 \mu \mathrm{m}$ ) were compared.

The main part of the experimental work devoted to the in-situ XRD analysis of the phases' formation during reactive sintering of FeAl25 compressed powder mixtures containing two above mentioned iron powder fractions $(<10 \mu \mathrm{m}$ and $<250 \mu \mathrm{m})$. These experiments were conducted at Hasylab, DESY Hamburg using the X-ray beam with $100 \mathrm{keV}$ (corresponding to the wavelength of $0.123894 \AA$ ) energy on DORIS III storage ring, BW5 experimental stage. For the analyses, Perkin Elmer XRD 1621 AN/CN ultra-fast Xray detector was utilized. Both modes of experiments were used the continuous heating regime and the isothermal one. In continuous heating regime, separated piece of compressed powder mixture of approx. $75 \mathrm{mg}$ (same as for DTA) was applied, while the isothermal mode enabled to use the whole cylindrical sample. The sample-to-detector distance was set to $1387.661 \mathrm{~mm}$ and $1270.931 \mathrm{~mm}$ for continuous heating mode and isothermal mode, respectively. In continuous heating regime, samples were heated from the laboratory temperature to $900{ }^{\circ} \mathrm{C}$ with the heating rate of $10 \mathrm{~K} \mathrm{~min}^{-1}$ as in DTA. The isothermal mode consisted of inserting 

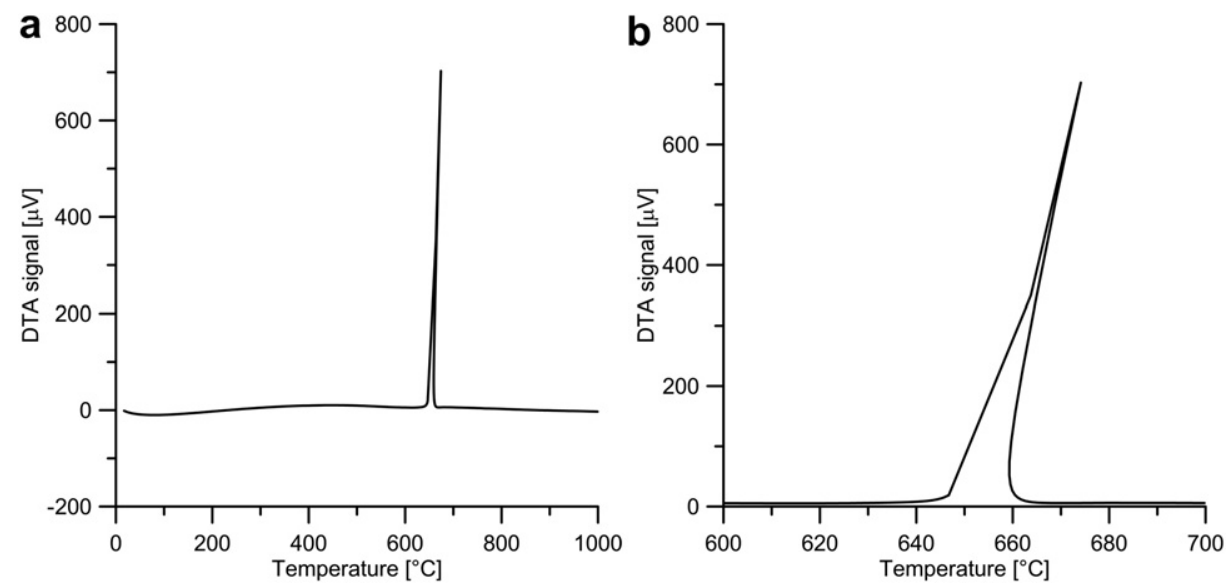

Fig. 2. DTA heating curve of FeAl25 compressed powder mixture (a), detail of the curve around the melting point of aluminium (b).

the sample directly to the furnace preheated to $800^{\circ} \mathrm{C}$ and reactive sintering for $300 \mathrm{~s}$. In both modes, XRD patterns were acquired each 3 s. Laue diffraction patterns were integrated to conventional intensity-angle dependence by Fit2D software and solved using an PANalytical HighScore Plus Software with PDF2 database. MATLAB system was used to normalize and visualise the time and temperature dependence of the phase composition in 3D. The microstructure of sintered samples was observed by the means of Olympus PME3 light microscope and TESCAN VEGA 3 LMU scanning electron microscope equipped with OXFORD Instruments INCA 350 EDS analyser. Phase composition of SHS products was also checked by conventional X-ray diffraction (XRD) using a PANalytical X'Pert Pro X-ray diffractometer.

In order to reveal the kinetics of reactions occurring during the reactive sintering, macro-scale model was used. This model consisted of the bulk iron ( $99.7 \mathrm{wt}$.\% purity), exposed to solid and liquid aluminium at 650 and $800{ }^{\circ} \mathrm{C}$, respectively. The reaction kinetics was studied by measuring the thickness of the individual layers of intermetallics by SEM-EDS and image analysis using Image $1.45 \mathrm{~s}$ software. Due to non-uniformity of the layers, the thickness was measured on acquired images each $50 \mu \mathrm{m}$ of the interface length and average value was calculated.

The process controlling the formation of intermetallics was determined by fitting the layer thickness by a linear or parabolic growth equation. A linear growth mode (1) can be found, when the process is controlled by the rate of chemical reaction producing the intermetallic layer.

$d=K(t-\tau)$

In this equation, $d$ is the layer thickness, $K$ is the linear rate constant, $t$ and $\tau$ are the reaction time and incubation period, respectively. When a process is controlled by diffusion of species through a reaction product, it is generally described by the parabolic law [31], written as:

$d^{2}=k \cdot t$

where $k$ is the parabolic rate constant.

\section{Results}

\subsection{Thermal analysis}

DTA was applied to reveal the thermal effects accompanying intermetallics' formation during continuous heating from the laboratory temperature to $900{ }^{\circ} \mathrm{C}$. On the heating curve, only one thermal effect was observed - an exothermic peak starting at approx. $645{ }^{\circ} \mathrm{C}$ (Fig. 2a and b). The slope of the heating curve increases when the temperature achieves melting point of aluminium $\left(660{ }^{\circ} \mathrm{C}\right)$. It indicates that the rate of intermetallics' formation on the solid-liquid interface is higher than in solidsolid contact. These highly exothermic reactions are superposed with the endothermic melting of aluminium, resulting in one observed exothermic peak.

In the isothermal mode, compressed powder mixtures were heated to $800{ }^{\circ} \mathrm{C}$ with the heating rate over $400 \mathrm{~K} \mathrm{~min}^{-1}$ and annealed isothermally. The temperature profile of the reactions was recorded by thermal camera. On both heating curves, four parts of the heating curve can be recognized, see Fig. 3. Region " 1 " represents heating of the compressed powder mixture without any phase transformation or chemical reaction. After that, the slope of the heating curve reduces (Part "2") as the aluminium melts, consuming energy and lowering the temperature increase. In the case of powder mixture containing coarse iron particles, the melting of aluminium starts after longer time, probably due to

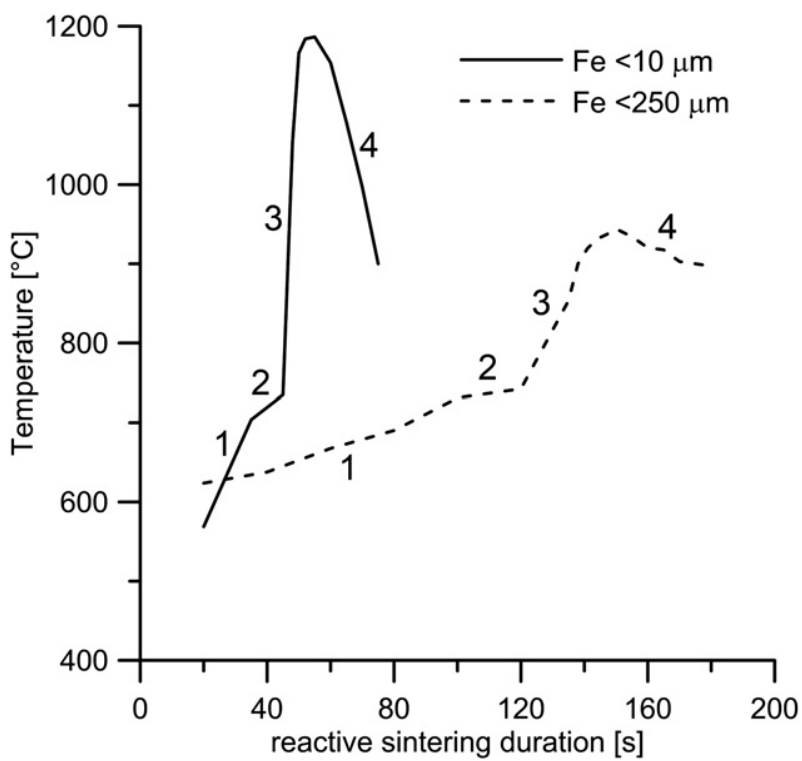

Fig. 3. Temperature-time dependence of the reactive sintering process of FeAl25 compressed powder mixture (recorded by thermal camera). 
a
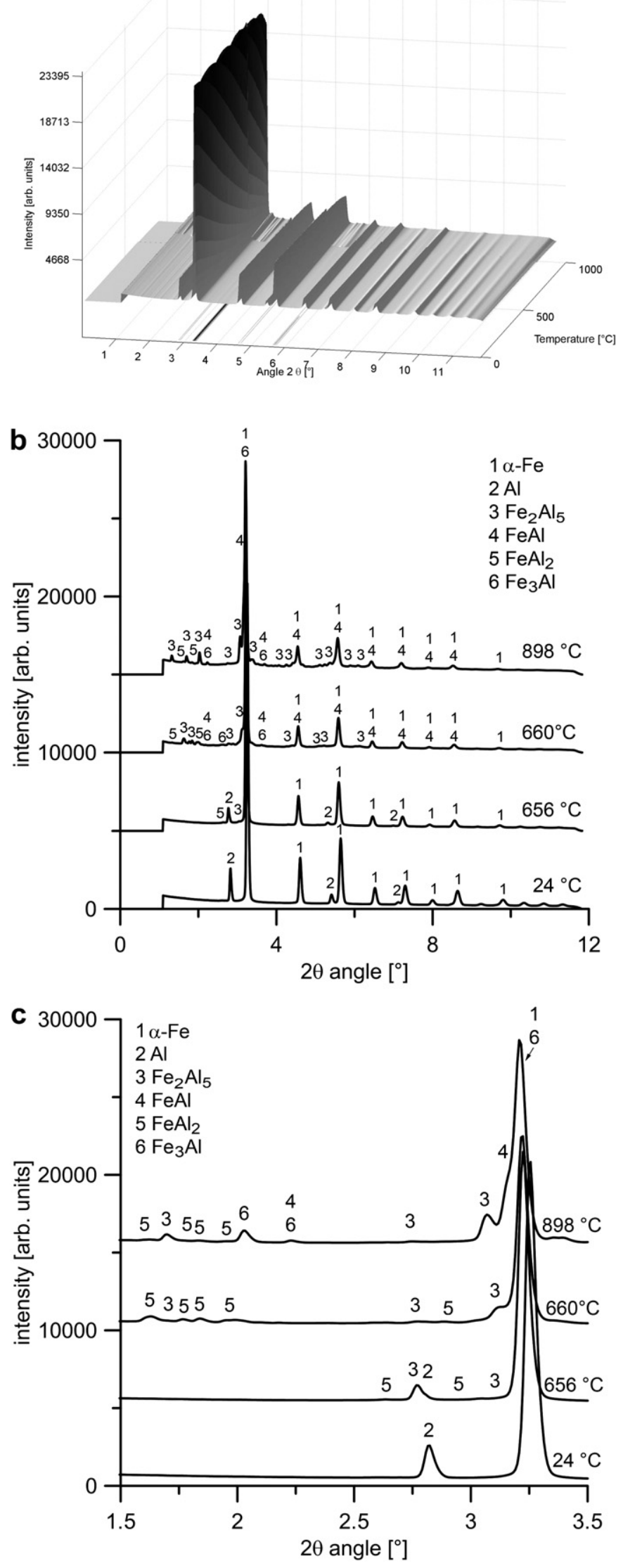

different thermal conduction in presence of coarse iron particles. After melting of aluminium, strongly exothermic formation of intermetallics starts (part "3"). The maximum temperature achieved in presence of fine iron particles is approx. $1190{ }^{\circ} \mathrm{C}$, while for coarse iron the maximum temperature was significantly lower $\left(944^{\circ} \mathrm{C}\right)$. The heating rate achieved by the exothermic reactions in stage "3" is approx. $28 \mathrm{~K} \mathrm{~s}^{-1}$ and $7 \mathrm{~K} \mathrm{~s}^{-1}$ for fine and coarse iron respectively. These values were obtained by thermal camera which records heating rate all volume of sample. The heating rate at the SHS reaction front is probably significantly higher. These results show that the formation of intermetallics starts after melting of aluminium in the case of high heating rate (over $400 \mathrm{~K} \mathrm{~min}^{-1}$ ). This result is in agreement with [32], where the shift of the intermetallics' formation to higher temperatures with increasing heating rate is described. Phase " 4 " represents cooling of the samples down to the temperature in the furnace. In the case of the sample containing coarse iron powder, there are also two minor thermal effects to be observed in regions " 3 " and " 4 ", being probably related to the $\alpha$-Fe $\rightarrow \gamma$-Fe and $\gamma$-Fe $\rightarrow \alpha$-Fe transformations as shown below.

\subsection{In situ X-ray diffraction during continuous heating}

In order to explain the behaviour observed during DTA, in situ XRD experiments were carried out with the same heating rate $\left(10 \mathrm{~K} \mathrm{~min}^{-1}\right)$. To avoid the application of the inert gas on the beamline, evacuated capillary $\left(10^{-2} \mathrm{~Pa}\right)$ was used instead of argon flow to suppress the oxidation. This experiment revealed traces of $\mathrm{FeAl}_{2}$ and $\mathrm{Fe}_{2} \mathrm{Al}_{5}$ phases few ${ }^{\circ} \mathrm{C}$ below the melting point of aluminium, see Fig. 4a, b and c. Immediately after the melting of aluminium, high amounts of $\mathrm{Fe}_{2} \mathrm{Al}_{5}, \mathrm{FeAl}_{2}$ are formed. At first, the peaks of $\mathrm{Fe}_{2} \mathrm{Al}_{5}$ phase are wider, which shows possible partial melting of this phase (Fig. 4b). When the temperature increases, the these phases are continuously transformed to $\mathrm{FeAl}$ and $\mathrm{Fe}_{3} \mathrm{Al}$ phases (Fig. $4 \mathrm{a}, \mathrm{b}$ and c). The intensities of $\mathrm{Fe}_{2} \mathrm{Al}_{5}$ increase during heating, but $\mathrm{FeAl}_{2}$ phase's signal reduces, see Fig. 4c.

\subsection{In situ X-ray diffraction during isothermal annealing}

The XRD experiment presented above aimed to model the conditions of DTA. However, our recommended reactive sintering route for aluminides and silicides requires extremely high heating rates $[19,20]$. Such conditions can be easily achieved by inserting the sample into a furnace preheated to the reactive sintering temperature. This experimental setup was applied in isothermal insitu experiment, aiming to simulate real reactive sintering as closely as possible. Temperature of $800{ }^{\circ} \mathrm{C}$ and the type of the powder mixture identical as in continuous heating experiment (fine iron powder and coarse mechanically prepared aluminium particles) were utilized in this experiment. In this setup, aluminium particles melt at first, directly followed by the formation of $\mathrm{Fe}_{2} \mathrm{Al}_{5}$, $\mathrm{FeAl}_{2}, \mathrm{FeAl}$ and $\mathrm{Fe}_{3} \mathrm{Al}$ phases (Fig. 5a and b). The widening of the $\mathrm{Fe}_{2} \mathrm{Al}_{5}$ diffraction lines was observed immediately after this phase had formed. The $\mathrm{Fe}_{3} \mathrm{Al}$ phase continuously disappears during the process, being converted to FeAl.

To describe the effect of the particle size, the isothermal experiment was carried out using coarser iron particles $(<250 \mu \mathrm{m}$, purity $99.5 \mathrm{wt} . \%)$, while the size of aluminium powder particles remained unchanged. In this case, similar behaviour was observed,

Fig. 4. XRD patterns of FeAl25 compressed powder mixture during heating with the rate of $10 \mathrm{~K} \mathrm{~min}^{-1}$ (iron particle size $<10 \mu \mathrm{m}$ ): a) full temperature dependence, b) selected diffraction patterns, c) low-angle detail of the XRD patterns. 

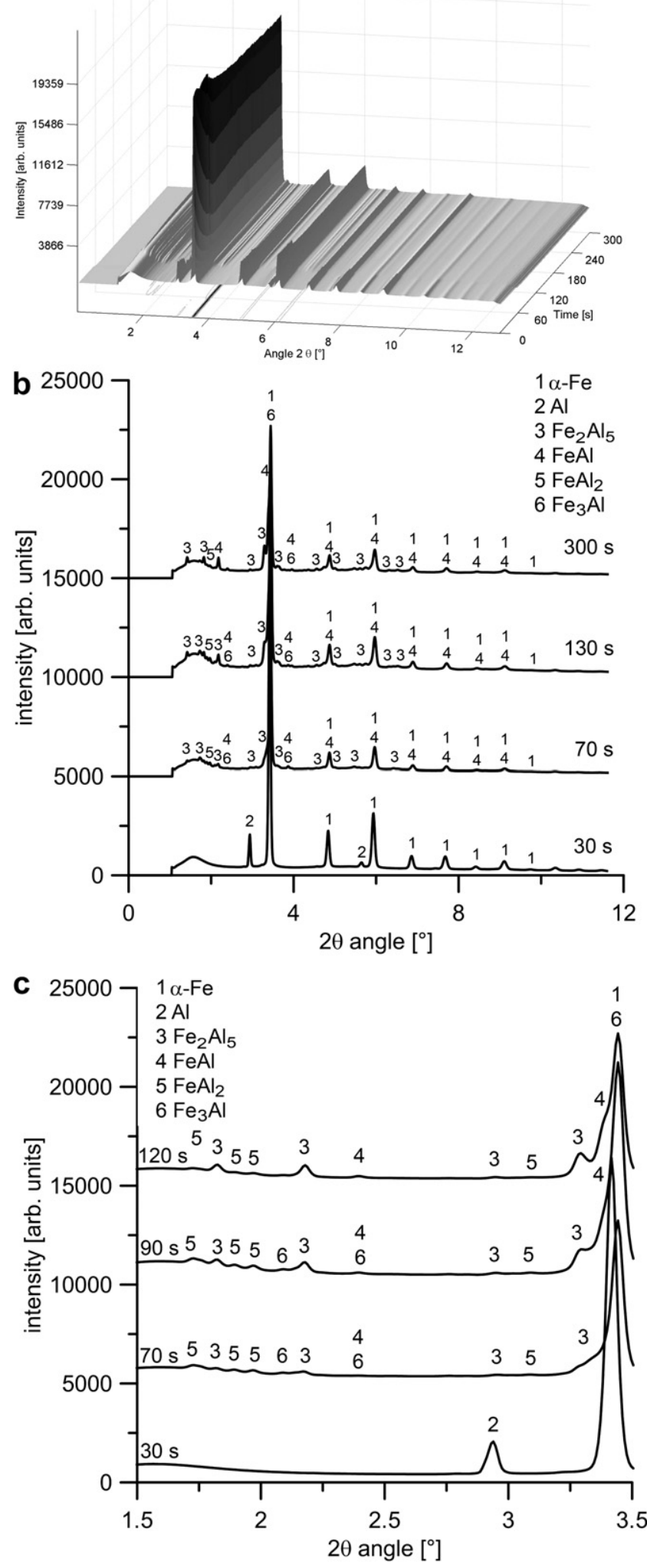

Fig. 5. XRD patterns of FeAl25 compressed powder mixture (iron particles size $<10 \mu \mathrm{m}$ ) during isothermal annealing at $800{ }^{\circ} \mathrm{C}$ : a) full time dependence, b) selected diffraction patterns, c) low-angle detail of the XRD patterns. i.e. aluminium melts and after that intermetallics $\left(\mathrm{Fe}_{2} \mathrm{Al}_{5}, \mathrm{FeAl}_{2}\right.$, $\mathrm{FeAl}$ and $\mathrm{Fe}_{3} \mathrm{Al}$ ) arise (Fig. 6a, b and c). In addition to these phases, $\gamma$-iron was determined when the formation of intermetallics started (Fig. 6b). After the formation of intermetallics had been completed, the $\gamma$-iron slowly changed to $\alpha$-iron.

\subsection{Microstructure and phase composition of reactive sintering products}

All samples after reactive sintering are composed of $\mathrm{Fe}_{2} \mathrm{Al}_{5}$, $\mathrm{FeAl}$ and small fraction of $\mathrm{FeAl}_{2}$ phase, as identified by both EDS and XRD analyses. FeAl phase surrounds the $\mathrm{Fe}_{2} \mathrm{Al}_{5}$ areas, while $\mathrm{FeAl}_{2}$ is located inside them (Fig. 7a and b). In addition to these intermetallics, unreacted iron and small areas of $\mathrm{Fe}_{3} \mathrm{Al}$ phase were identified. Both the fraction of unreacted iron in the reactive sintering product and the porosity increase with the diameter of iron powder particles, see Fig. 7a and b. In the samples prepared by rapid heating and isothermal annealing for $300 \mathrm{~s}$, the porosity values are $42 \mathrm{vol} . \%$ and 69 vol.\% for fine and coarse iron respectively. Porosity is also strongly affected by the heating rate. The sample containing fine iron heated with the rate of $10 \mathrm{~K} \mathrm{~min}^{-1}$ reaches the porosity of approx. 62 vol.\%.

To confirm the temporary formation of $\gamma$-iron during reactive sintering of compressed powder mixtures with coarse iron, following experiment was performed: Coarse powder of carbon steel (ASTM A576 grade) was obtained by mechanical machining. FeAl25C compressed powder mixture was prepared using this powder. Reactive sintering was carried out at $800{ }^{\circ} \mathrm{C}$. After the ignition of the SHS reactions, sample was water-quenched immediately. In this sample, martensite (metastable solid solution of carbon in iron) was identified, having typical needle-like morphology, see Fig. 8. Since martensite can be obtained only by rapid cooling or mechanical deformation of austenite phase (solid solution of carbon in $\gamma$-iron), it indicates that $\gamma$-iron was present during reactive sintering. In this sample, representing the early stages of reactive sintering, $\mathrm{Fe}_{2} \mathrm{Al}_{5}$ phase was identified around the martensite regions. FeAl phase was found only in small areas, accompanying the $\mathrm{Fe}_{2} \mathrm{Al}_{5}$ phase. Unreacted aluminium particles can be also seen in the structure of this sample (Fig. 9). Inside aluminium particles that were molten during reactive sintering, needle-like $\mathrm{FeAl}_{3}$ particles were identified by SEM-EDS. This phase was not found by the in-situ XRD analysis. Due to the strongly exothermic nature of the reaction forming the $\mathrm{Fe}_{2} \mathrm{Al}_{5}$, the temperature inside the reaction mixture can exceed the melting point of the $\mathrm{Fe}_{2} \mathrm{Al}_{5}\left(1169{ }^{\circ} \mathrm{C}\right)$ and $\mathrm{FeAl}_{3}\left(1160{ }^{\circ} \mathrm{C}\right)$ phases (Fig. 1). Due to concentration fluctuations in the melt, $\mathrm{FeAl}_{3}$ is probably able to crystallize during water quenching. As the reactions and diffusion proceed, the local concentrations of aluminium and iron are changing and therefore this phase is not identified in the final product. When the reaction mixture has been quenched in the early stage of the SHS process, $\mathrm{FeAl}_{3}$ phase is obtained. These facts indicate that at least some of these phases crystallize from the melt during SHS.

For the comparison, long-term reactive sintering at $800{ }^{\circ} \mathrm{C}$ for $72 \mathrm{~h}$ was also carried out. During this process, binary FeAl25 alloy containing fine iron powder was fully transferred to FeAl ordered phase (Fig. 9a). On the contrary, utilization of coarse iron powder resulted in heterogeneous product containing $\mathrm{FeAl}$ and $\mathrm{Fe}_{3} \mathrm{Al}$ phases as well as the unreacted iron and aluminium (Fig. 9b).

\subsection{Macro-scale model of reactive sintering process}

The above presented results showed that $\mathrm{Fe}-\mathrm{Al}$ phases emerge mainly on the interface between solid iron particles and molten aluminium. Since it is almost impossible to describe the kinetics of 
a
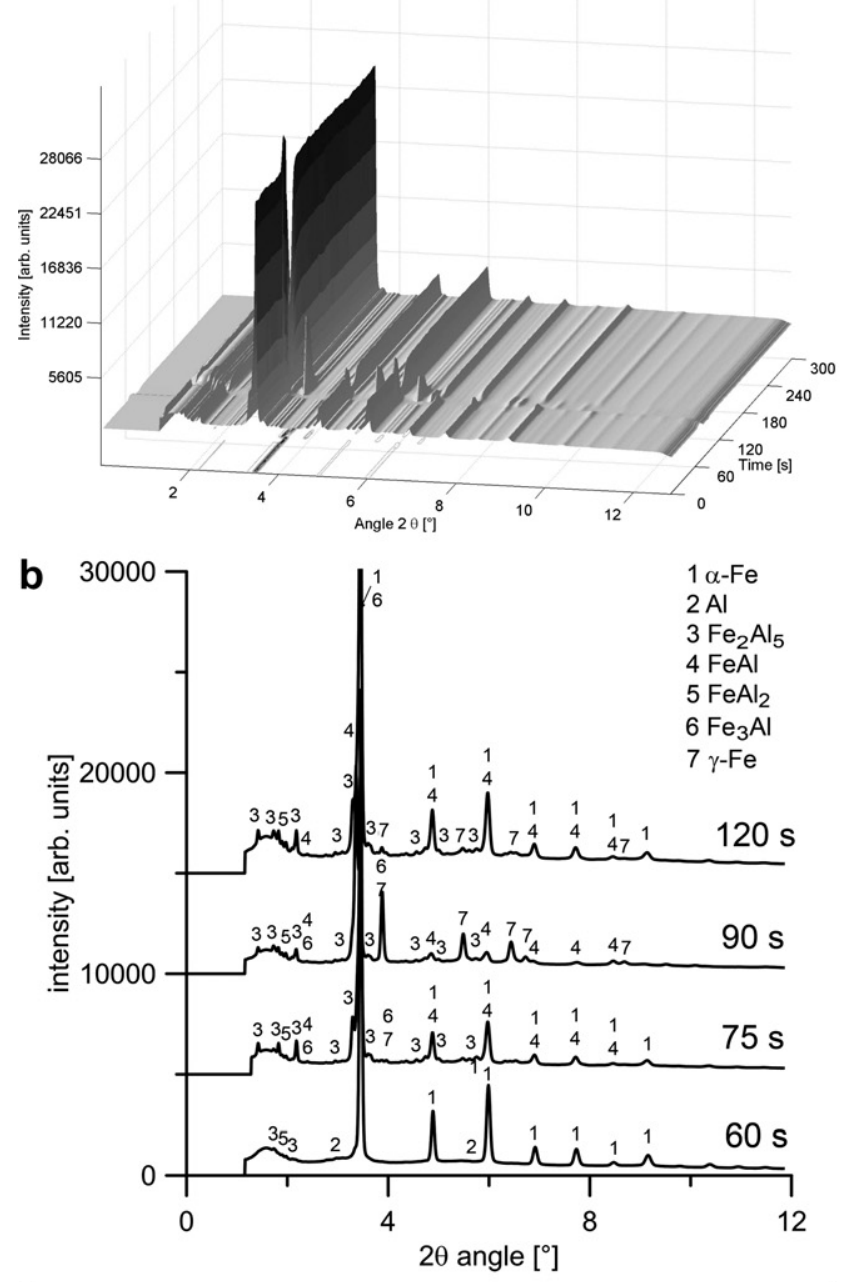

C

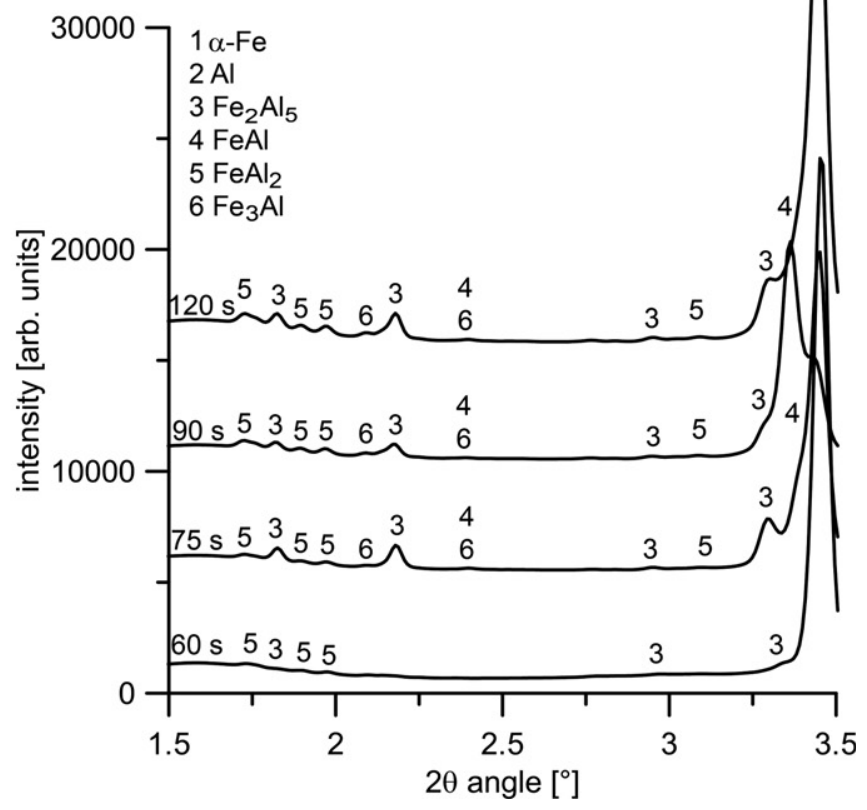

the intermetallics' formation on a real compressed powder mixture, the macro-scale model consisting of bulk solid iron sample submerged to molten aluminium at $800{ }^{\circ} \mathrm{C}$ was applied. After $\mathrm{Fe}+\mathrm{Al}$ reactions had completed, layers of $\mathrm{Fe}_{2} \mathrm{Al}_{5}$ and $\mathrm{FeAl}$ were observed. In addition to these phases, $\mathrm{FeAl}_{3}$ particles were found in solidified aluminium around the iron sample and small $\mathrm{FeAl}_{2}$ regions inside the $\mathrm{Fe}_{2} \mathrm{Al}_{5}$ layer (Fig. 10). The time dependence of the thickness of both $\mathrm{Fe}_{2} \mathrm{Al}_{5}$ a FeAl layers is parabolic, thus indicating diffusion-controlled reactions (Fig. 11). Most probably, the formation of $\mathrm{Fe}-\mathrm{Al}$ phases is controlled by the inward diffusion of aluminium. Therefore, the parabolic rate constant for $\mathrm{Fe}_{2} \mathrm{Al}_{5}$ and FeAl phases were calculated by the Eq. (2). Results in Table 1 show that the parabolic rate constant for $\mathrm{Fe}_{2} \mathrm{Al}_{5}$ phase is $8 \pm 0.8 \times 10^{-11} \mathrm{~m}^{2} \mathrm{~s}^{-1}$ during the first 20 min of submersion in liquid aluminium. After that it decreases to $3.5 \pm 0.6 \times 10^{-11} \mathrm{~m}^{2} \mathrm{~s}^{-1}$. The decrease in rate constant of $\mathrm{Fe}_{2} \mathrm{Al}_{5}$ phase is probably caused by the formation of FeAl phase. When the FeAl phase is formed, iron from the iron-side of the $\mathrm{Fe}_{2} \mathrm{Al}_{5}$ layer is consumed. Therefore, the growth of $\mathrm{Fe}_{2} \mathrm{Al}_{5}$ is decelerated. The parabolic rate constant of $\mathrm{FeAl}$ phase fluctuates between 7 and $7.5 \times 10^{-15} \mathrm{~m}^{2} \mathrm{~s}^{-1}$ without any significant time dependence.

The porosity of the intermetallics' layers was assessed by the image analysis. The results revealed that the volume fraction of pores increases with the reaction time (Table 1 ). The maximum value is approx. 25 vol.\% which corresponds with the values presented as the lowest porosity obtainable by pressureless reactive sintering of $\mathrm{Fe}-\mathrm{Al}$ alloys [9].

To describe the kinetics of the formation of intermetallics below the melting point of aluminium, the model consisting of lowcarbon steel pin in solid aluminium annealed at $650{ }^{\circ} \mathrm{C}$ was applied. The layers containing $\mathrm{Fe}_{2} \mathrm{Al}_{5}$ and $\mathrm{FeAl}_{2}$ phases were obtained, see Fig. 12. The parabolic rate constant of this process is $2 \pm 0.5 \times 10^{-15} \mathrm{~m}^{2} \mathrm{~s}^{-1}$. This value is much lower than the rate of formation of $\mathrm{Fe}_{2} \mathrm{Al}_{5}$ phase in solid-liquid reaction. It can be concluded that major part of intermetallics is formed over the melting point of aluminium.

\section{Discussion}

Following mechanism is proposed (Fig. 13), using all of the results presented above: Presented results confirmed that the phases' formation mechanism strongly depends on the heating rate, as previously published in [32]. During continuous heating, traces of $\mathrm{Fe}_{2} \mathrm{Al}_{5}$ and $\mathrm{FeAl}_{2}$ phases arise below the melting point of aluminium. After aluminium is molten, the formation of these phases is accelerated. During fast heating and isothermal annealing, the $\mathrm{Fe}+\mathrm{Al}$ reactions initiate after melting of aluminium. After that, the mechanism is almost the same. The fact that the solid state reaction does not take place is probably a reason for lower porosity of the sample prepared in isothermal mode. In this case, the molten aluminium fills the pores in compressed powder mixture before the intermetallics are formed.

This exothermic reaction evolves the heat that gives a rise to the temperature close to $1200{ }^{\circ} \mathrm{C}$ in the reaction front. This value is sufficient to melt the $\mathrm{Fe}_{2} \mathrm{Al}_{5}$ phase [16]. Partial melting of this phase was confirmed by widening of its diffraction lines. Due to endothermic melting, the temperature decreases and $\mathrm{Fe}_{2} \mathrm{Al}_{5}$ and $\mathrm{FeAl}_{2}$ phases precipitate. $\mathrm{Fe}_{2} \mathrm{Al}_{5}$ and $\mathrm{FeAl}_{2}$ high-aluminium phases consume high amount of aluminium and therefore a part of iron content remains unreacted.

Fig. 6. XRD patterns of FeAl 25 compressed powder mixture (iron particles size $<250 \mu \mathrm{m}$ ) during isothermal annealing at $800^{\circ} \mathrm{C}$ : a) full time dependence, b) selected diffraction patterns, c) low-angle detail of the XRD patterns. 

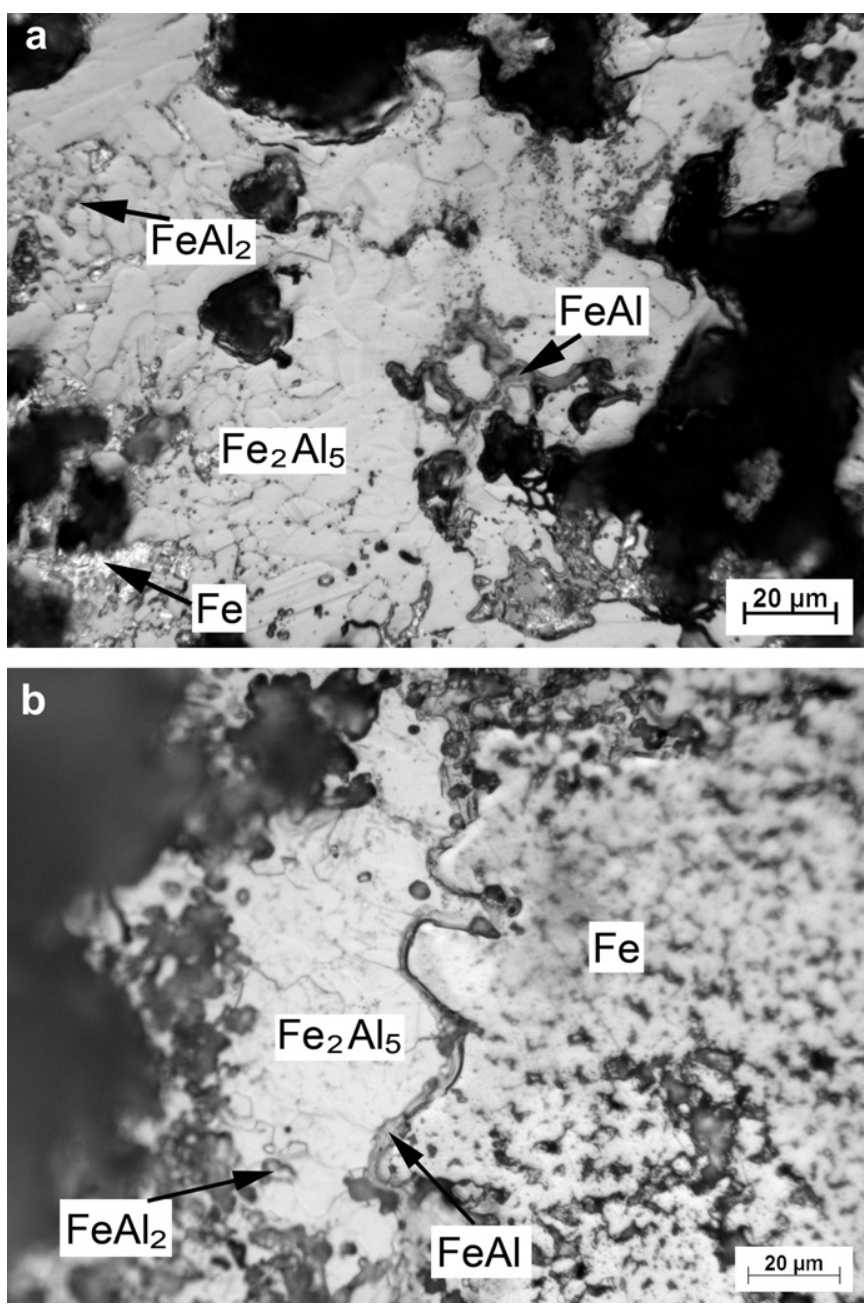

Fig. 7. Microstructure of FeAl25 alloys produced by reactive sintering at $800{ }^{\circ} \mathrm{C}$ for $300 \mathrm{~s}$ : a) using iron powder particle size $<10 \mu \mathrm{m}$, b) iron powder particle size $<250 \mu \mathrm{m}$.

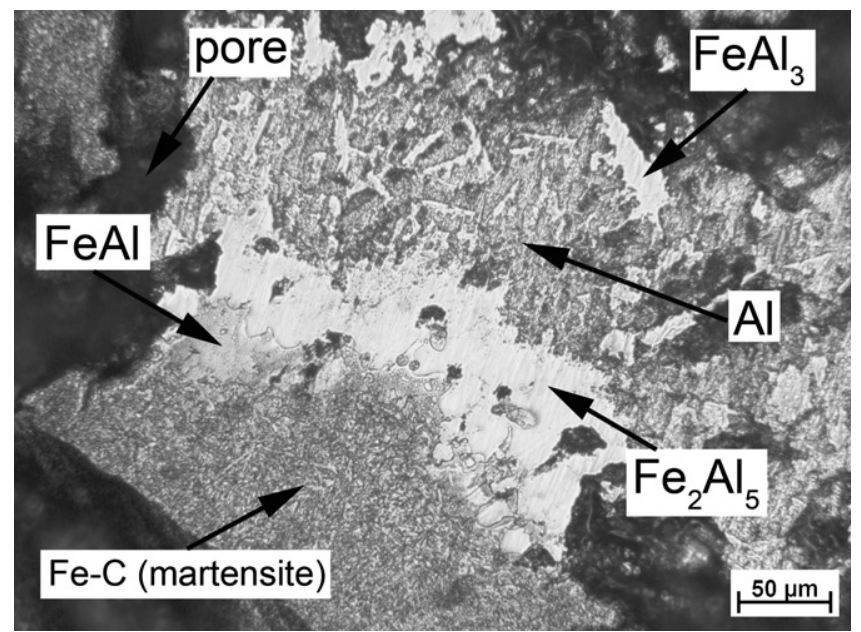

Fig. 8. Microstructure of FeAl25C alloy quenched during the early stages of SHS process.
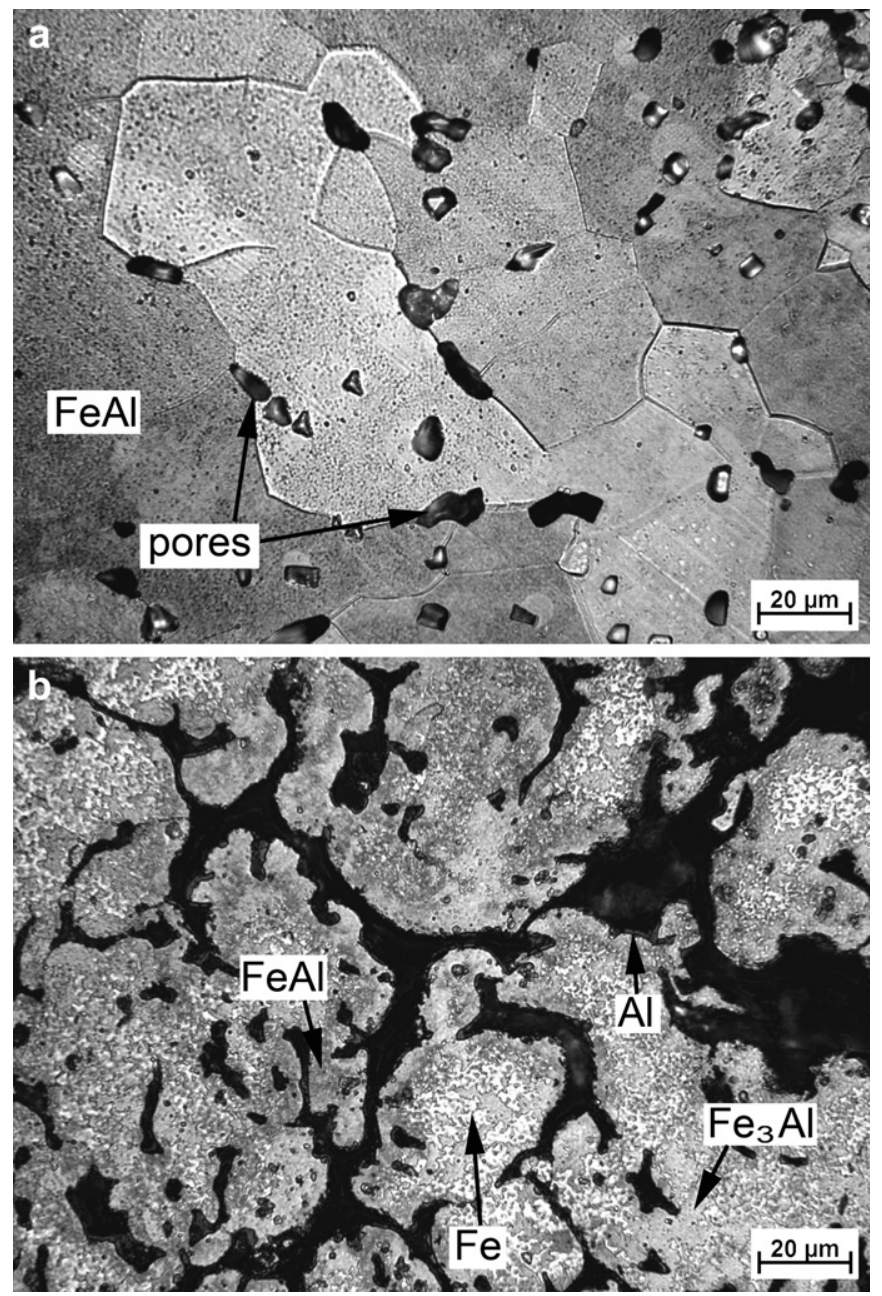

Fig. 9. Microstructure of FeAl25 alloy prepared by reactive sintering at $800{ }^{\circ} \mathrm{C}$ for $72 \mathrm{~h}$ a) using fine iron powder, b) using coarse iron powder.

After $\mathrm{Fe}_{2} \mathrm{Al}_{5}$ phase is formed, it starts to react with iron, producing $\mathrm{FeAl}$ phase. $\mathrm{Fe}_{3} \mathrm{Al}$ phase arises as a transient phase between iron and FeAl, being continuously transformed to FeAl. After long reaction time (e.g. $72 \mathrm{~h}$ tested in this work), the structure

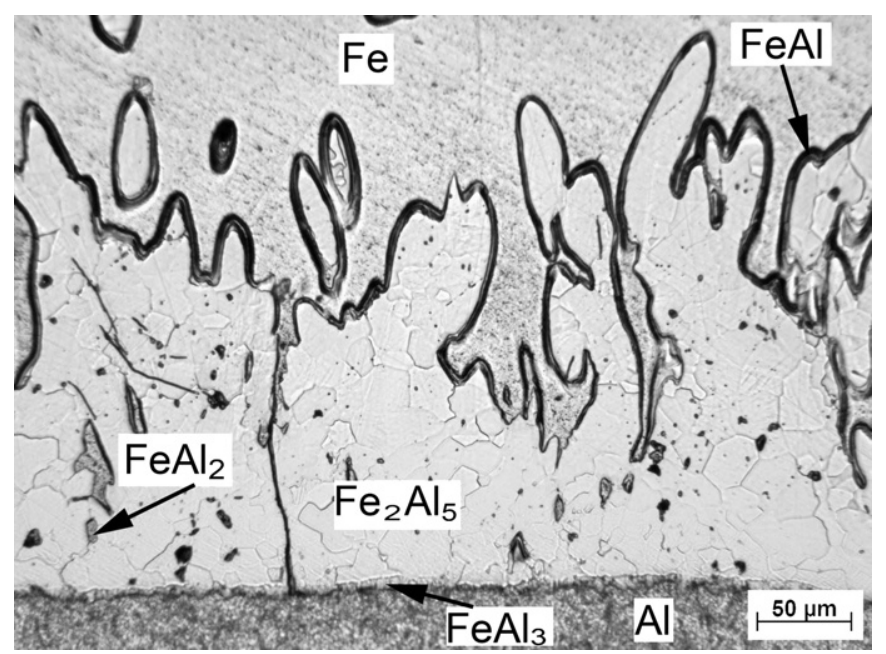

Fig. 10. Microstructure of intermetallics' layers on iron obtained by submersion in molten aluminium at $800{ }^{\circ} \mathrm{C}$ for $10 \mathrm{~min}$. 

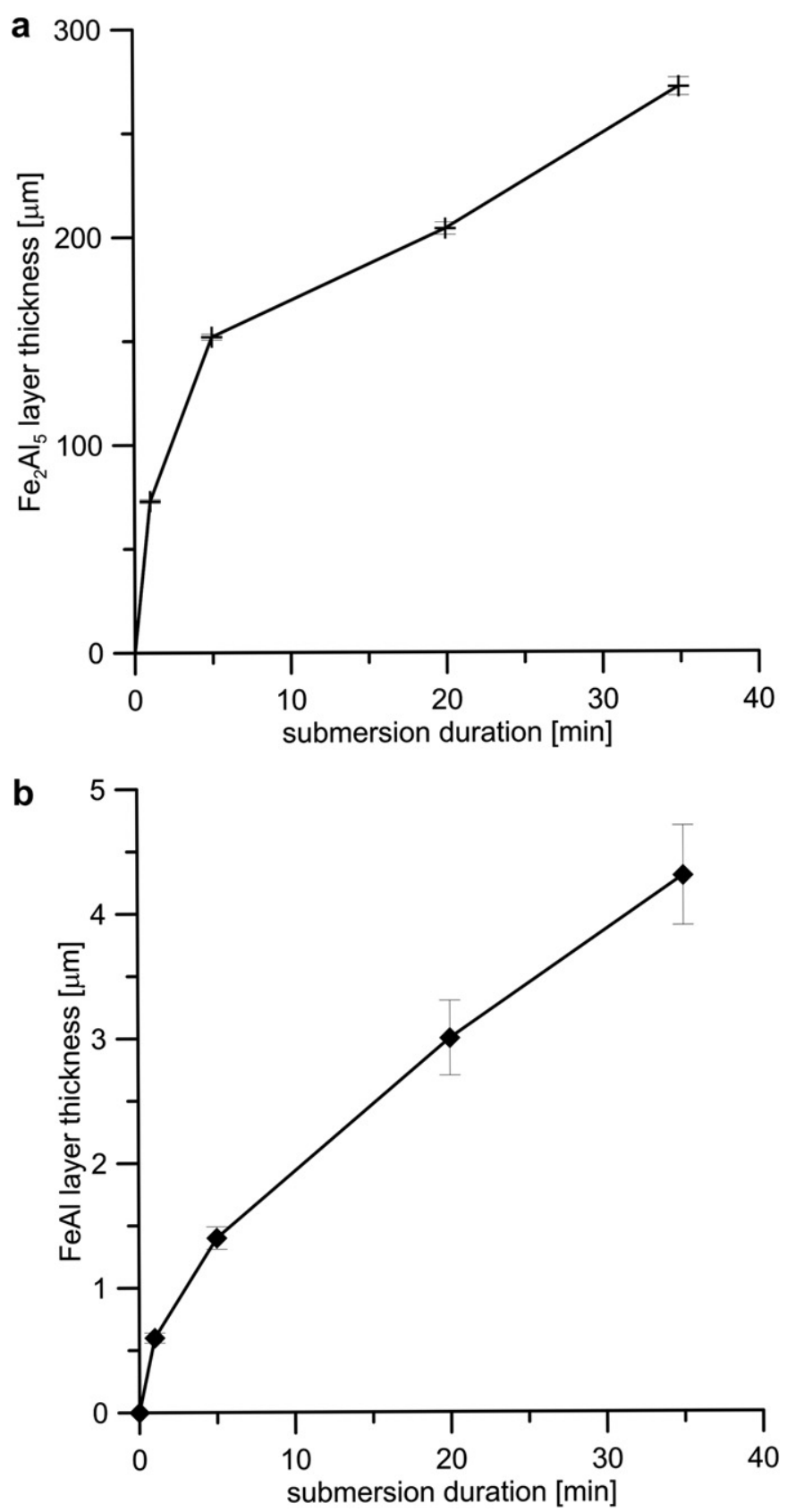

Fig. 11. Time dependence of the thickness of $\mathrm{Fe}_{2} \mathrm{Al}_{5}$ (a) and $\mathrm{FeAl}$ (b) layers during submersion in molten aluminium at $800{ }^{\circ} \mathrm{C}$.

is fully transformed to FeAl phase. For this reason, nearly pure FeAl phase was observed after reactive sintering in our previous work [7].

When coarse iron particles were applied, the mechanism is expected to be the similar with these exceptions: After $\mathrm{Fe}_{2} \mathrm{Al}_{5}$ is

Table 1

Parabolic rate constants of $\mathrm{Fe}_{2} \mathrm{Al}_{5}$ and FeAl phases $\left[\mathrm{m}^{2} \mathrm{~s}^{-1}\right]$ at $800{ }^{\circ} \mathrm{C}$ and the porosity of intermetallics' layers [vol.\%] in dependence on the reaction duration.

\begin{tabular}{llll}
\hline $\begin{array}{l}\text { time } \\
{[\mathrm{min}]}\end{array}$ & $k\left(\mathrm{Fe}_{2} \mathrm{Al}_{5}\right)$ & $k(\mathrm{FeAl})$ & $\begin{array}{l}\text { Layer porosity } \\
{[\text { vol.\%] }}\end{array}$ \\
\hline 1 & {$\left[0.10^{-11} \mathrm{~m}^{2} \mathrm{~s}^{-1}\right]$} & {$\left[0.10^{-15} \mathrm{~m}^{2} \mathrm{~s}^{-1}\right]$} & 2 \\
5 & 8.9 & 7.0 & 3 \\
20 & 7.7 & 7.5 & 6 \\
35 & 3.4 & 7.5 & 16 \\
\hline
\end{tabular}

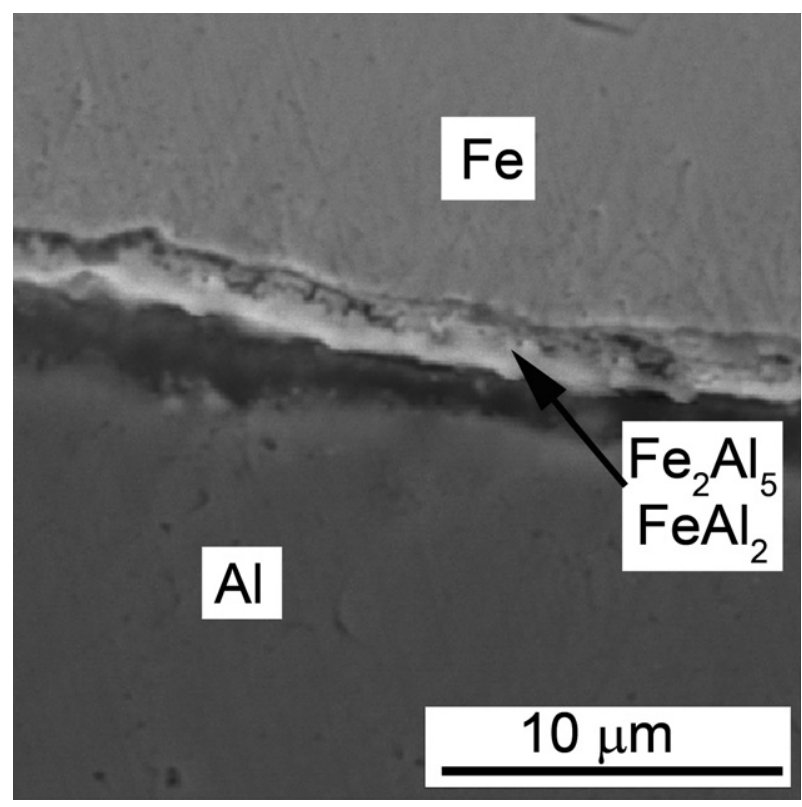

Fig. 12. Microstructure of intermetallics' layers on iron obtained by the reaction with solid aluminium at $650{ }^{\circ} \mathrm{C}$ for $30 \mathrm{~min}$.

created by the $\mathrm{Fe}+\mathrm{Al}$ reaction, high portion of the heat is probably transferred to iron particles, thus lowering the overall sample temperature. The iron particles are heated above $\alpha \rightarrow \gamma$ transformation temperature. According to the phase diagram published in [16], the solubility of aluminium in $\gamma$-iron is low and therefore the interactions of iron with aluminium on the interface are limited. In addition to this effect, $\alpha \rightarrow \gamma$ transformation is endothermic, thus lowering the temperature at the reaction front to max. $950{ }^{\circ} \mathrm{C}$ recorded by thermal camera. The real temperature of the SHS front reaction is probably significantly higher which guarantees highaluminium phases melting. Therefore the structure of the longterm annealed sample containing coarse iron particles is inhomogeneous and contains $\mathrm{FeAl}$ and $\mathrm{Fe}_{3} \mathrm{Al}$ phases as well as unreacted iron and aluminium.

High porosity of SHS Fe-Al alloys is usually explained in connection with the phases' formation [33] and Kikendall's phenomenon [15]. In this paper we endeavoured to divide the porosity to two types - the pores connected directly with the reactions and "technological" pores. The first type comprises small pores with the diameter below $1 \mu \mathrm{m}$ that may arise from the shrinkage due to lattice changes when forming new phases [12] and rounded mid-size pores up to $30 \mu \mathrm{m}$. Rounded shape of the pores usually indicates gas porosity. So they may be a confirmation of the above proposed mechanism dealing with local melting of high-aluminium phases on the combustion front. Chen et al. described the formation of similar type of pores during SHS in vacuum due to aluminium evaporation [34]. Our experiments were carried out under atmospheric pressure in argon or in lower vacuum $\left(10^{-2} \mathrm{~Pa}\right)$, therefore this effect was not observed. The pores probably contain residual air after pressing. The largest irregular pores have the shape of initial aluminium particles that were applied for the samples preparation. Their presence can be explained by the fact that the solubility of aluminium in iron is much higher than opposite. Therefore, the flux of aluminium atoms will be compensated by a migration of vacancies resulting in porosity formation [12,35]. In addition, the diffusivity of iron in aluminium is much higher than that of aluminium in iron, causing Kirkendall's effect [15]. During pressureless reactive sintering, the 

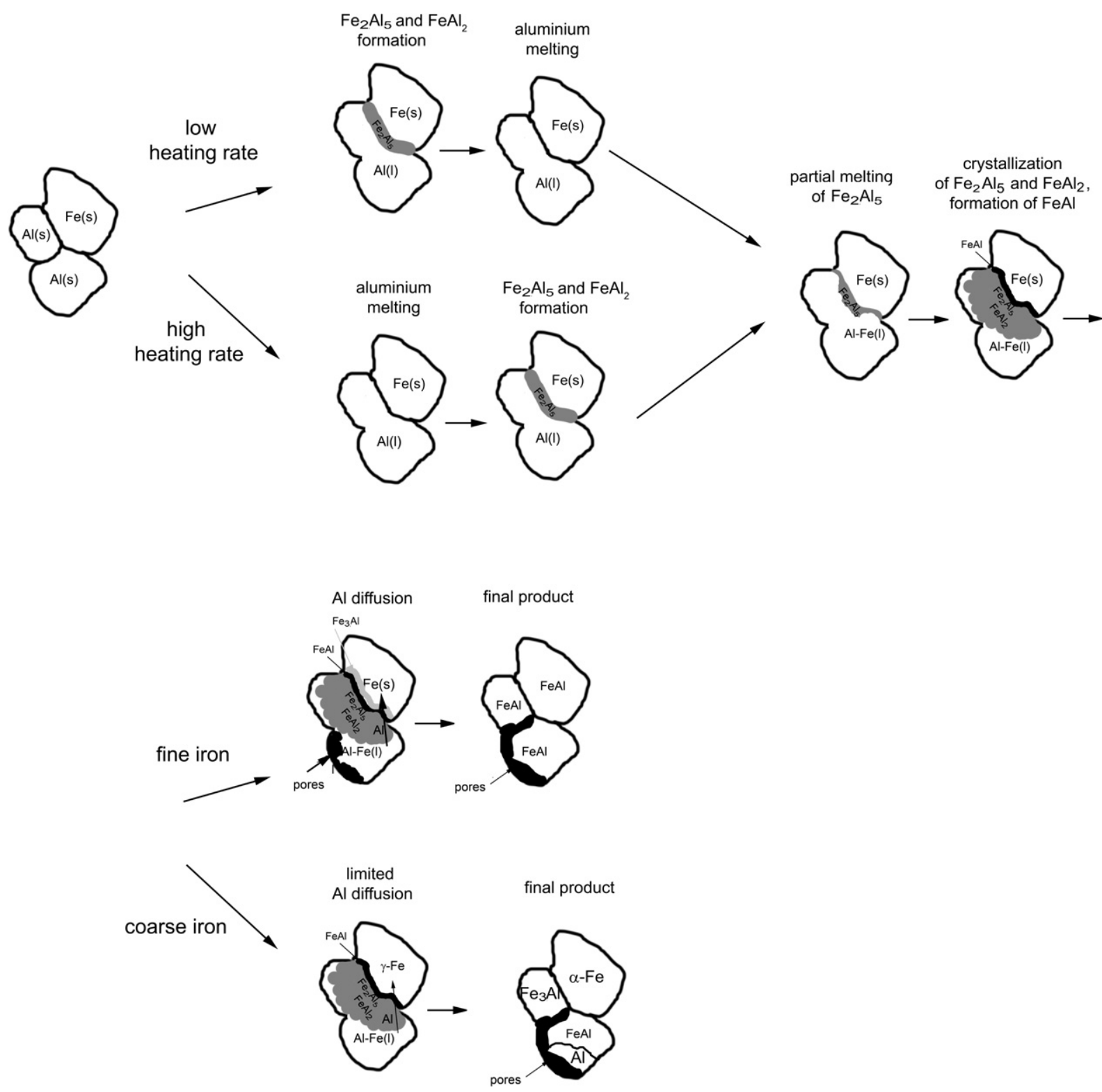

Fig. 13. Proposed mechanism of SHS reactions in $\mathrm{FeAl}_{25}$ alloy.

second type of porosity can be minimized by using very fine aluminium particles, but the first one cannot be excluded. It was proved by macro-scale model, where these pores were also observed in similar amount.

\section{Conclusion}

This paper aimed to describe the mechanism of the phases' formation during SHS preparation of $\mathrm{Fe}-\mathrm{Al}$ alloys. Thermal analysis, in-situ XRD and macro-scale modelling of the process were applied. The results showed that the initiation temperature strongly depends on the heating rate. During slower heating $\left(10 \mathrm{~K} \mathrm{~min}^{-1}\right)$, the formation of $\mathrm{Fe}_{2} \mathrm{Al}_{5}$ and $\mathrm{FeAl}_{2}$ intermetallics starts below the melting point of aluminium. When the heating rate is high (over $400 \mathrm{~K} \mathrm{~min}^{-1}$ ), intermetallics are created after melting of aluminium. It lowers the porosity of the product. During long-term annealing, all of the phases can be transformed to FeAl phase when fine powders were applied. Detailed mechanism, dealing with the partial melting of $\mathrm{Fe}_{2} \mathrm{Al}_{5}$ phase on the reaction front, is proposed in this paper. The formation of $\mathrm{Fe}-\mathrm{Al}$ phases is probably controlled by the inward diffusion of aluminium.

\section{Acknowledgement}

This research was financially supported by Czech Science Foundation, project No. P108/12/G043 and by Grant Agency of ASCR, project No. KAN300100801. Authors also thank to Hasylab, DESY Hamburg for allowing them to perform the in-situ XRD analyses on the BW5 beamline.

\section{References}

[1] Kratochvíl P. Intermetallics 2008;16:587.

[2] Sikka VK, Wilkening D, Liebetrau J, Mackey B. Materials Science and Engineering A 1998;258:229.

[3] Šíma V, Kratochvíl P, Kozelský P, Schindler I, Hána P. International Journal of Materials Research 2009;100:382. 
[4] Kopeček J, Haušild P, Jurek K, Jarošová M, Drahokoupil J, Novák P, et al. Intermetallics 2010;18:1327-31.

[5] Schindler I, Kratochvíl P, Prokopčáková P, Kozelský P. Intermetallics 2010;18: 745-7.

[6] Józwiak S, Karczewski K, Bojar Z. Intermetallics 2010;18:1332.

[7] Novák P, Knotek V, Šerák J, Michalcová A, Vojtěch D. Powder Metallurgy 2011; 54:167-72.

[8] Novák P, Vojtěch D, Šerák J, Kubásek J, Průša F, Knotek V, et al. Chemické Listy 2009;103:1022.

[9] Rabin BH, Wright RN. US patent 5269830; 1993.

[10] Murakami K, Nishida N, Osamura K, Tomota Y, Suzuki T. Acta Materialia 2004; 52:217.

[11] Gedevanishvili S, Deevi SC. Materials Science and Engineering A 2002; 325:163.

[12] Kang HZ, Hu CT. Materials Chemistry and Physics 2004;88:264

[13] Paul A, van Dal MJH, Kodentsov AA, van Loo FJJ. Acta Materialia 2004;52:623-30.

[14] Nakamura R, Takasawa K, Yamazaki Y, Iijima Y. Intermetallics 2002;10: 195-204.

[15] Gao H, He Y, Shen P, Zou J, Xu N, Jiang Y, et al. Intermetallics 2009;17:1041-6

[16] Massalski TB. Binary alloy phase diagrams. Materials Park: ASM International; 1990

[17] Vogel SC, Stein F, Palm M. Applied Physics A 2010;99:607.

[18] Novák P, Knotek V, Voděrová M, Kubásek J, Šerák J, Michalcová A, et al. Journal of Alloys and Compounds 2010;497:90-4.

[19] Rabin BH, Wright RN. Metallurgical and Materials Transactions A 1992;23: 35-40.

[20] Joslin DL, Easton DS, Liu CT, Babu SS, David SA. Intermetallics 1995;3:467-81.
[21] Heckel RW, Yamada M, Ouchi C, Hickl AJ. Thin Solid Films 1977;45:367.

[22] Hibino A. Materials Transactions 2010;51:516-24.

[23] Vrel D, Girodon-Boulandet N, Paris S, Mazué JF, Couqueberg E, Gailhanou M, et al. Review of Scientific Instruments 2001;73:422-9.

[24] Charlot F, Bernard F, Gaffet E, Klein D, Niepce JC. Acta Materialia 1999;47: 619-29.

[25] Niepce JC. International Journal of Self-Propagating High-Temperature Synthesis 2007;16:235-55.

[26] Brajpuriya R, Tripathi S, Sharma A, Chaudhari SM, Phase DM, Gupta Ajay, et al. Applied Surface Science 2007;253:8584-7.

[27] Paris S, Gaffet E, Vrel D, Thiaudiere D, Gailhanou M, Bernard F. Science of Sintering 2005;37:27-34.

[28] Novák P, Michalcová A, Šerák J, Vojtěch D, Fabián T, Randáková S, et al. Journal of Alloys and Compounds 2009;470:123-6.

[29] Novák P, Popela T, Kubásek J, Šerák J, Vojtěch D, Michalcová A. Powder Metallurgy 2011:54:50-5.

[30] Novák P, Michalcová A, Voděrová M, Šíma M, Šerák J, Vojtěch D, et al. Journal of Alloys and Compounds 2010;493:81-6.

[31] Pieraggi B. Oxidation of Metals 1987;27:177-85.

[32] Chojnacki M, Józwiak S, Karczewski K, Bojar Z. Intermetallics 2011;19: 1555-62.

[33] Shen PZ, He YH, Gao HY, Zou J, Xu NP, Jiang Y, et al. Desalination 2009;249: 29-33.

[34] Chen G, Cao P, He Y, Shen P, Gao H. Journal of Materials Science 2012;47: 1244-50.

[35] Sheasby JS. International Journal of Powder Metallurgy and Powder Technology 1979;15:301-5. 